\title{
TRATAMENTOS SIMPLIFICADOS PARA GERMINAÇÃO DE SEMENTES DE TARUMÃ (Vitex megapotamica (SPRENG.) MOLDENKE.)
}

\author{
Simplified Treatments for Taruma (Vitex megapotamica \\ (Spreng.) Moldenke.) Seed Germination
}

\author{
Eduardo Vianna \\ Engenheiro Agrônomo formado pela PUCPR, Curitiba - PR. e-mail: alexandre.koehler@pucpr.br \\ Alexandre Bernardi Koehler \\ Engenheiro Florestal, M. Sc., Professor de Silvicultura do Curso de Agronomia da PUCPR, Curitiba - PR. e-mail: \\ alexandre.koehler@pucpr.br
}

\begin{abstract}
Resumo
No Viveiro Florestal da PUCPR, Tijucas do Sul, Paraná, foi conduzido um experimento com o objetivo de avaliar métodos para quebra de dormência de sementes de tarumã - Vitex megapotamica. Foram efetuados testes de germinação no laboratório e em estufa. O experimento em estufa testou quatro diferentes métodos: a) imersão em água sob temperatura ambiente (durante 24 horas), b) imersão em água a $80^{\circ} \mathrm{C}$ (até o equilíbrio térmico entre a água e o ambiente), c) escarificação manual, d) semeadura direta (testemunha). Os resultados obtidos mostraram que o método de imersão em água quente não deve ser utilizado para a quebra de dormência em sementes de tarumã e que os métodos de imersão em água sob temperatura ambiente e de escarificação manual podem ser utilizados para obter-se uma germinação mais uniforme, mas apenas beneficiar as sementes e semeá-las diretamente é a melhor opção.
\end{abstract}

Palavras-chave: Vitex megapotamica; Sementes; Germinação.

\begin{abstract}
In the tree nursery of PUCPR, in Tijucas do Sul, state of Parana, was lead an experiment with the objective to evaluate methods for seeds dormancy break of taruma -Vitex megapotamica. Germination tests were carried out in the laboratory and in a greenhouse. Four different methods were conducted experimentally in the greenhouse: a) seed immersion in water under environment temperature (during 24 hours); b) seed immersion in hot water (until the thermal balance among the water and the environment);c) manual scarification; d) direct sowing (control). The results showed that the seed immersion in hot water can not be used for the seeds dormancy break of taruma, and the seed immersion in water under environment temperature and manual scarification can be used to reach a more uniform germination, but the preparation and directly sown of the seeds is the best option.
\end{abstract}

Keywords: Vitex megapotamica; Seeds; Germination. 


\section{INTRODUÇÃO}

A espécie Vitex megapotamica (Spreng.) Moldenke, conhecida popularmente como tarumã, é uma árvore da família Lamiaceae (ex-Verbenaceae) que ocorre sobre uma vasta área, desde os estados de Minas Gerais e Mato Grosso do Sul até o Rio Grande do Sul, e ainda na Argentina, Paraguai e Uruguai. No estado do Paraná, ocorre na Floresta Ombrófila Mista e na Floresta Estacional Semidecidual (CARVALHO, 2007). Trata-se de uma espécie de crescimento lento, com incremento médio de $1,70 \mathrm{~m}^{3} \mathrm{ha}^{-1}$ ano $^{-1}$, que pode atingir grande porte, com até $25 \mathrm{~m}$ de altura e $120 \mathrm{~cm}$ de diâmetro (CARVALHO, 2007).

A árvore é extremamente ornamental, podendo ser empregada com sucesso em projetos de paisagismo e arborização urbana (LORENZI, 2002). É uma das principais espécies recomendadas em planos de recuperação de matas ciliares degradadas, dado seu caráter higrófilo (BARDDAL, 2006; CURCIO et al., 2007). A madeira do tarumã tem densidade de $0,67 \mathrm{~g} / \mathrm{cm}^{3}$ (CARVALHO, 2007). Ela é bastante procurada devido à sua resistência mecânica e durabilidade elevada quando exposta ao ambiente externo e em contato com o solo, motivo pelo qual se recomenda a espécie para o desdobro em postes, moirões e vigas (LORENZI, 2002).

Os frutos da espécie são drupas carnosas, arredondadas ou ovaladas, pubescentes, de coloração arroxeada e medem de 1 a $2 \mathrm{~cm}$ de comprimento. A árvore floresce no final da primavera e início do verão. Os frutos amadurecem entre o final de janeiro e início de abril (observações dos autores). Os frutos, doces e comestíveis, representam importante fonte de alimento para a fauna, sendo apreciados por aves, peixes, macacos e pequenos mamíferos. A espécie tem ainda propriedades medicinais, sendo citada como diurética, depurativa e anti-reumática e bom potencial apícola (CARVALHO, 2007; BACKES; IRGANG, 2002; LONGHI, 1995).

As sementes encerram cerca de 3930 unidades por quilograma (BARDDAL, 2006). A principio, essas necessitam de tratamentos pré-germinativos para a quebra de dormência (FINEP/UFPR, 1981). Lorenzi (2002) sugere a utilização de substrato organo-argiloso e condicionamento em ambiente semi-sombreado para a quebra de dormência. Regagnin (não publicado) apud Schorn (2007) recomenda a remoção da polpa e imersão em água durante 12 horas.

Segundo Lorenzi (2002), as sementes de tarumã possuem uma taxa de germinação muito baixa, abaixo de 10\%, e sua emergência ocorre entre 40 e 60 dias. Por sua vez, Carvalho (no prelo) cita taxas de germinação em torno de 50\%. Barddal (2006) registrou taxas de 70\%, mas este autor ressaltou que a viabilidade das sementes varia significativamente entre diferentes anos de colheita.

Para o beneficiamento das sementes, Barddal (2006) recomenda a maceração em uma base áspera envolta por uma camada de areia grossa. Embora as sementes sejam recalcitrantes, suportam até três meses de armazenamento sem perder o poder germinativo (REITZ; KLEIN; REIS, 1983). De acordo com as características de posição, textura e exposição de seus cotilédones, suas plântulas podem ser inseridas no grupo morfofuncional das fanero-epígeo-foliáceas (BARDDAL, 2006).

\section{MATERIAL E MÉTODOS}

O experimento foi realizado no Viveiro Florestal da PUCPR, localizado no Município de Tijucas do Sul, Estado do Paraná. A montagem do experimento deu-se em abril de 2003 e os resultados foram observados entre os meses de maio e junho de 2003.

Foi utilizada uma matriz de sementes, encontrada no Município de Tijucas do Sul, PR, região situada no Primeiro Planalto Paranaense, dentro dos domínios da Floresta Ombrófila Mista Montana, conforme Veloso, Rangel-Filho e Lima (1991). As temperaturas médias da região variam de $18^{\circ} \mathrm{C}$ até $22^{\circ} \mathrm{C}$, para os meses frios e quentes, respectivamente. O clima predominante é do tipo $\mathrm{Cfb}$, caracterizado como subtropical úmido, mesotérmico, de verões frescos e com ocorrência de geadas severas no inverno (PUCPR/IFSE, 2003).

Os frutos com as sementes de tarumã foram colhidos no dia 30 de março de 2003 diretamente da árvore, logo após o início da queda espontânea. Esses foram beneficiados com maceração em peneira 
de malha metálica sob água corrente. As sementes foram mantidas à sombra durante dois dias, antes da montagem do experimento de germinação.

Foram aplicados 4 métodos simplificados para efetuar a quebra de dormência em ambiente de estufa: Ta) imersão em água sob temperatura ambiente (durante 24 horas), Tb) imersão em água quente $\left.\left(80^{\circ} \mathrm{C}\right), \mathrm{Tc}\right)$ escarificação manual com lixa grossa, Td) semeadura direta (testemunha).

Para cada tratamento, foram aplicadas 6 (seis) repetições, com 10 (dez) unidades amostrais cada. As sementes foram semeadas em tubetes plásticos de $30 \times 120 \mathrm{~mm}$, em substrato padronizado, composto de terra preta $(60 \%)$, húmus de minhoca $(20 \%)$, vermiculita $(10 \%)$ e casca de pínus triturada $(10 \%)$. A germinação foi acompanhada em intervalos de 7 dias, durante 60 dias. Diariamente, procedeuse a irrigação do experimento, sempre no início da manhã.

Foi também conduzido o teste de germinação no laboratório de sementes do Centro de Ciências Agrárias e Ambientais da Pontifícia Universidade Católica do Paraná. Neste caso, foram utilizadas 4 placas "ger-box", sendo 2 com vermiculita e 2 com papel toalha, contendo 50 sementes de tarumã em cada uma. As placas contendo as sementes foram colocadas em câmara germinadora a $30^{\circ} \mathrm{C}$ e umidade relativa de $80 \%$ e observadas semanalmente, durante 60 dias, entre os meses de maio e julho de 2003.

\section{RESULTADOS E DISCUSSÃO}

A porcentagem de germinação acumulada estabilizou-se em torno $70 \%$ decorridos 40 dias do início do experimento. O substrato de germinação não representou um efeito significativo na porcentagem final de sementes germinadas, conforme a tendência das curvas de germinação (FIGURA 1).

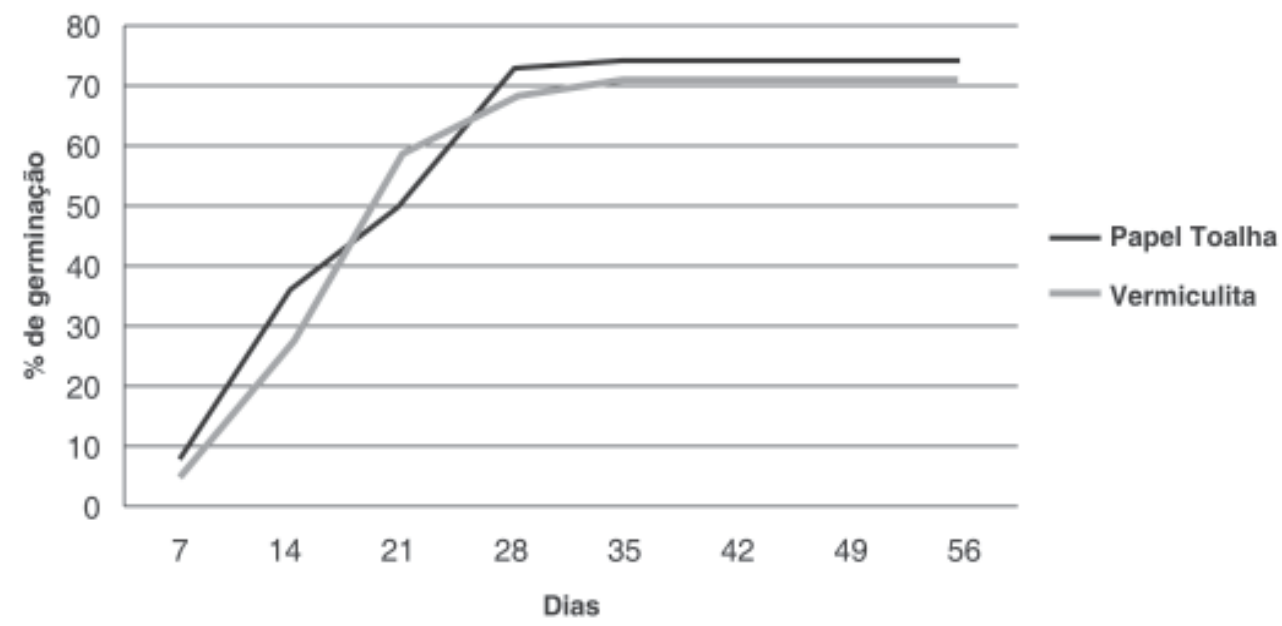

FIGURA 1 - Porcentagem de germinação de sementes de tarumã na câmara germinadora do laboratório de sementes da PUCPR

Figure 1 - Germination percentage of taruma seeds, inside the germination chamber in the seed laboratory, PUCPR 
Na Tabela 1, verifica-se que o tratamento testemunha resultou na maior porcentagem de germinação, quando comparado com a escarificação manual e com a imersão em água fria, embora inexistam diferenças estatísticas significativas entre os tratamentos Ta, Tc e Td. O tratamento com água quente resultou em uma taxa de germinação nula, o que indica a inviabilidade de tal procedimento para as sementes de tarumã.

TABELA 1 - Porcentagem de germinação de sementes de taruma, sob diferentes tratamentos, ao final de 60 dias de observação, em condições de estufa, no viveiro florestal da PUCPR

Table 1 - Germination percentage of taruma seeds under different treatments, after 60 days of observation, in greenhouse conditions, at the tree nursery of PUCPR

\begin{tabular}{lr}
\hline Tratamentos & Médias $(\%)^{*}$ \\
\hline Imersão em água fria (Ta) & $56,7 \mathrm{a}$ \\
Imersão em água quente (Tb) & $0,00 \mathrm{~b}$ \\
Escarificação manual (Tc) & $71,7 \mathrm{a}$ \\
Testemunha (Td) & $76,7 \mathrm{a}$ \\
\hline
\end{tabular}

* Médias acompanhadas da mesma letra não diferem significativamente entre si, segundo teste de Tukey a 5\% de propabilidade.

Os resultados obtidos se aproximam dos apresentados por Barddal (2007). No experimento desse autor, as sementes foram imersas em água fria durante 7,14, 21 e 28 dias. O referido autor observou que para a espécie, a máxima germinação foi obtida com seis dias de imersão. No caso desse trabalho, a imersão foi de apenas 24 horas, mas o bom resultado obtido pelo tratamento controle mostra que esta técnica não é melhor do que a simples semeadura direta após o beneficiamento dos frutos.

As porcentagens de germinação observadas no viveiro e em laboratório são semelhantes, o que mostra que nem mesmo o ambiente controlado pode favorecer uma maior taxa de germinação. Isso significa que, em termos práticos, o viveirista pode recorrer à semeadura direta, fícando atento à composição de um substrato adequado e à irrigação diária.

\section{CONCLUSÕES}

Os resultados mostram que as sementes de tarumã não requerem necessariamente tratamentos pré-germinativos e que se podem obter boas taxas de germinação em semeadura direta, com o cuidado de manter o substrato sempre bem irrigado.

Diante dos resultados obtidos, recomenda-se para coleta de sementes observar a época em que se inicia a queda espontânea dos frutos. Uma vez no viveiro, o imediato despolpamento e plantio são procedimentos recomendáveis para garantir boas taxas de germinação. Para otimizar o uso de espaço dos canteiros, recomenda-se a germinação em sementeiras com posterior repicagem para as embalagens individuais. 


\section{REFERÊNCIAS}

BACKES, P.; IRGANG, B. Árvores do sul: guia de identificação e interesse ecológico. As principais espécies árboreas sul-brasileiras. Um programa: Instituto Souza Cruz Clube da Árvore, p. 326, 2002.

BARDDAL, M. L. A influência da saturação hídrica na distribuição de oito espécies arbóreas da floresta ombrófila mista aluvial do rio Iguaçu, Paraná, Brasil. 130 f. Tese (Doutorado) - Setor de Ciências Agrárias, Universidade Federal do Paraná, Curitiba, 2006.

CARVALHO, P. E. R. Espécies arbóreas brasileiras. Brasília: EMBRAPA Informação Tecnológica, 2007. v. 2. No prelo.

CURCIO, G. R. et al. Recomendação de espécies arbóreas nativas, por tipo de solo, para recuperação ambiental das margens da represa do rio Iraí, Pinhais. Floresta. Curitiba, v. 37, n. 1, jan./abr. 2007.

FINEP-UFPR. Plano básico de estudos de sementes e mudas de essências florestais nativas. Curitiba: FINEP-UFPR, 1981. p. 125.

LONGHI, A. Livro das árvores: árvores e arvoretas do sul. Porto Alegre: L\&PM, 1995. p. 174.

LORENZI, H. Árvores brasileiras: manual de identificação e cultivo de plantas arbóreas nativas do Brasil. Nova Odessa: Plantarium, 2002. p. 360.

PUCPR/IFSE. Vivat floresta sistemas ecológicos. Curitiba: Champagnat, 2003. p. 63.

REITZ, R; KLEIN, R. M; REIS, A. Projeto madeira do Rio Grande do Sul. Porto Alegre: Secretaria da Agricultura e de Abastecimento, 1983. p. 524.

SCHORN, L. A.; FORMENTO, S. Apostila de silvicultura II: produção de mudas. Blumenau: Universidade Regional de Blumenau, 2003. 58 p. Disponível em: <http://home.furb.br/lschorn/silvi/ 2/Apostila\%20Silvicultura.PDF>. Acesso em: 31 jul. 2007.

VELOSO, H.; RANGEL-FILHO, A. L. R.; LIMA, J. C. A. Classificação da vegetação brasileira adaptada à um sistema universal. Rio de Janeiro: IBGE, 1991. p. 112.

Recebido em: 08/03/2006

Received in: 03/08/2006 Aprovado em: 30/09/2006 Accepted in: 30/09/2006 